\title{
Utilização de coberturas comestíveis para redução de absorção de gordura em produtos estruturados pré-fritos congelados de mandioca
}

\author{
Use of edible coatings to reduce fat absorption in frozen \\ pre-fried structured cassava products
}

\section{Autores | Authors}

凶Shirley Aparecida Garcia BERBARI

Instituto de Tecnologia de Alimentos (ITAL) Centro de $P$ \& $D$ de Hortifrutícolas Av. Brasil, 2880, Chapadão CEP: $13070-178$ Campinas/SP - Brasil e-mail: sberbari@ital.sp.gov.br

Patricia PRATI

Agência Paulista de Tecnologia dos Agronegócios (APTA/Pólo Centro Sul) e-mail:pprati@apta.sp.gov.br

\section{Daniela De Grandi Castro} FREITAS

Empresa Brasileira de Pesquisa Agropecuária (EMBRAPA/ CTAA)

e-mail:daniela@ctaa.embrapa.br

Eduardo VICENTE

Rita de Cassia Salvucci Celeste ORMENESE

Instituto de Tecnologia de Alimentos (ITAL) Centro de Ciência e Qualidade de Alimentos

e-mail: evicente@ital.sp.gov.br ritaorm@ital.sp.gov.br

Farayde Matta FAKHOURI

Universidade Estadual de Campinas (UNICAMP)

Faculdade de Engenharia de Alimentos (FEA) e-mail: farayde@yahoo.com.br

凶 Autor Correspondente / Corresponding Author

Recebido / Received: 23/01/2009 Aprovado / Approved: 18/05/2011

\section{Resumo}

Este estudo objetivou avaliar o efeito de coberturas comestíveis como barreira à incorporação de óleo durante o processo de fritura em produtos estruturados pré-fritos congelados, produzidos com raiz de mandioca. Foram utilizados três diferentes hidrocoloides em seis formulações de coberturas, sendo três coberturas compostas por pectina e proteína de soro de leite, e outras três compostas por hidroxipropil-metil celulose e proteína de soro de leite nas proporções de 1:4, 1:1 e 4:1, respectivamente. Foram também produzidos filmes nas mesmas relações utilizadas para as coberturas e, nestes filmes, foram avaliadas a permeabilidade ao vapor de água, a solubilidade em água e a espessura, além das propriedades mecânicas (resistência à tração e elongação). Nos produtos de mandioca, foram avaliados os teores de umidade e lipídios, cor e textura instrumental, e atributos sensoriais. A concentração de proteína de soro de leite influenciou as propriedades dos filmes, provocando diminuição da solubilidade, aumento da espessura, aumento no valor da permeabilidade para os filmes compostos de pectina e redução significativa para os filmes compostos de hidroxopropil-metil celulose e proteína de soro de leite. As coberturas à base de hidroxipropil-metil celulose proporcionaram maiores teores de umidade e menores teores de lipídios nos produtos de mandioca, sendo que a combinação de 1:4 proporcionou uma redução de 32,3\% no teor de absorção de lipídios. A cobertura de hidroxipropil-metil celulose na combinação de 1:4 proporcionou ao produto maior crocância, além de coloração dourada, desejável neste tipo de produto. Sensorialmente, os produtos apresentaram diferenças estatísticas somente em relação aos atributos textura e crocância. A partir destes resultados, pode-se concluir então que esta interação, hidroxipropil-metil celulose e proteína de soro de leite na proporção 1:4, quando aplicada em produtos estruturados de mandioca pré-fritos congelados, proporciona menor retenção de lipídios, além de crocância e textura interna adequadas.

Palavras-chave: Mandioca; Coberturas comestíveis; Congelamento; Absorção de óleo; Fritura. 


\section{Summary}

The objective of this study was to evaluate the effect of edible coatings as a barrier to oil incorporation during the process of frying frozen pre-fried structured products made from cassava roots. Three different hydrocolloids were used in six coating formulations, three being composed of pectin and milk whey protein, and the other three of hydroxypropyl methyl cellulose and milk whey protein in the proportions of $1: 4,1: 1$ and $4: 1$, respectively. Films made with the same formulations were evaluated for their characteristics of water vapor permeability, water solubility and thickness, as well as their mechanical properties (tensile strength and stretching). The cassava products were evaluated for their moisture and lipid contents, color, instrumental texture and sensory attributes. The milk whey protein concentration influenced the characteristics of the bio-films, causing a decrease in solubility, increase in thickness and increase in the permeability value of the bio-films containing pectin, and a significant reduction of the same parameters in the bio-films composed of hydroxypropyl methyl cellulose and milk whey protein. The hydroxypropyl methyl cellulose based coatings resulted in higher moisture contents and lower lipid contents in the cassava products, the 1:4 combination giving a $32.30 \%$ reduction in the amount of lipid absorption. The hydroxypropyl methyl cellulose coating in the 1:4 proportion resulted in crispier products with a golden color, desirable attributes in this type of product. The products only presented statistically significant sensory differences for the attributes of texture and crispiness. As from these results it was concluded that the interaction of hydroxypropyl methyl cellulose with milk whey protein in the 1:4 proportion, when applied to frozen pre-fried structured cassava products, resulted in reduced lipid retention and adequate crispiness and internal texture.

Key words: Cassava; Edible coatings; Freezing; Oil absorption; Frying. 


\section{Introdução}

Os alimentos fritos contêm significativos teores de gordura, atingindo, em alguns casos, um terço do peso total do produto (MELLEMA, 2003). O desenvolvimento de produtos mais aceitáveis aos consumidores, cada vez mais conscientes e preocupados com a saúde, leva à necessidade da redução da incorporação de óleo durante o processo de fritura (MALLIKARJUNAN et al., 1997).

As propriedades da superfície do alimento têm grande importância na incorporação de óleo, o que torna a aplicação de coberturas uma via promissora. A cobertura pode ser fina e invisível, ou pode ser espessa, denominada "batters" (MELLEMA, 2003). Cobertura comestível pode ser definida como uma camada de material comestível formada ao redor do alimento ou colocada entre os componentes do mesmo (KROCHTA e MULDER-JOHNSON, 1997). Segundo Krochta et al. (1994), os filmes comestíveis diferem das coberturas comestíveis por serem formados antes da sua aplicação no produto, enquanto que a cobertura se forma durante a aplicação sobre o mesmo.

Para a elaboração de filmes comestíveis e/ ou biodegradáveis, é necessária a utilização de diversos componentes, de finalidade específica, constituídos de pelo menos um agente formador de filme (macromoléculas), solvente (água, etanol, entre outros), plastificante para atenuar a rigidez (glicerol, sorbitol, entre outros) e agente regulador de $\mathrm{pH}$. Entre as macromoléculas, os principais grupos utilizados são as proteínas, polissacarídeos e seus derivados, e lipídios (monoglicerídeos, ácidos graxos, ceras naturais e outros) (BERTAN, 2003).

Este trabalho teve como objetivo avaliar o efeito do uso de coberturas comestíveis compostas (proteínas do soro de leite, pectina e hidroxipropil metil celulose) na redução de óleo incorporado, na retenção de umidade e na qualidade do produto formatado de mandioca pré-frito e congelado (cor, textura e propriedades sensoriais).

\section{Material e métodos}

\subsection{Matéria-prima}

Foram utilizados $250 \mathrm{~kg}$ de raízes de mandioca (Manihot esculenta Crantz) da variedade IAC 576-70, adquiridas da região de Mogi das Cruzes-SP, colhidas aos 11 meses após o plantio. Os biopolímeros utilizados para a elaboração das coberturas compostas foram: proteína de soro de leite (Simplesse Dry 100, CP Kelko, Limeira, Brasil), pectina de baixo teor de metoxilação (Slendid type 200, CP Kelko, Limeira, Brasil) e hidroxipropil-metil celulose (Methocel, Tovani Benzaquen, São Paulo, Brasil). Glicerol (Sinth) foi utilizado como plastificante.

\subsection{Caracterização da matéria-prima}

Amostra da raiz fresca de mandioca foi caracterizada quanto às análises de sólidos totais e umidade (HORWITZ, 2000); açúcares totais e redutores (HORWITZ, 2000); proteína e lipídios totais (INSTITUTO ADOLFO LUTZ, 1985); cinzas (HORWITZ, 2000); fibras totais (HORWITZ, 2000); amido (método descrito por DIEMAIR, 1963); pH e acidez total (INSTITUTO ADOLFO LUTZ, 2005).

\subsection{Caracterização dos filmes}

- a) Aspecto visual: para cada tipo de filme produzido, foram realizadas análises visuais e táteis, visando utilizar apenas os filmes que fossem homogêneos (avaliação quanto à presença de partículas insolúveis e coloração uniforme), apresentassem continuidade (sem rupturas ou zonas quebradiças) e possibilitassem o manuseio. Os testes foram realizados em triplicatas.

- b) Propriedades de barreira: a permeabilidade ao vapor de água (PVA) foi determinada pelo método padrão E-96 modificado da ASTM (ASTM, 1995; TANADA-PALMU e GROSSO, 2002). Os testes foram realizados em triplicatas.

- c) Propriedades mecânicas: a resistência à tração e a porcentagem de elongação na ruptura foram determinadas utilizando um texturômetro TA-XT2 (Stable Micro Systems, Surrey, Grã-Bretanha), operado de acordo com o método padrão ASTM D 882-83, com separação inicial das garras e velocidade do probe de $50 \mathrm{~mm} . \mathrm{s}^{-1} \mathrm{e} 1 \mathrm{~mm} . \mathrm{s}^{-1}$, respectivamente. Os testes foram realizados em seis replicatas. A resistência à tração e a elongação foram calculadas de acordo com Tanada-Palmu et al. (2002).

- d) Espessura: a espessura dos filmes foi determinada através de micrômetro digital MDC-25M (Mitutoyo, MFG, Japão), sendo a média aritmética de 10 medidas aleatórias sobre a área do filme.

- e) Solubilidade: a solubilidade em água dos filmes foi determinada segundo o método proposto por Gontard et al. (1994). Os testes foram realizados em triplicatas.

- f) Opacidade: foi determinada segundo equação citada em Hunterlab (1997). Os testes foram realizados em triplicatas. 


\subsection{Elaboração e aplicação dos filmes (coberturas), e secagem}

Tanto nos filmes como nas coberturas compostas, foram utilizadas pectina e proteína de soro de leite, e hidroxipropil-metil celulose e proteína de soro de leite, nas proporções 1:1, 4:1 e 1:4. As soluções de hidroxipropilmetil celulose foram preparadas dispersando-se $2 \%$ hidroxipropil-metil celulose em $33 \%$ de água quente $\left(>70{ }^{\circ} \mathrm{C}\right)$ e foi adicionando-se, posteriormente, $65 \%$ de água gelada sob agitação. A solução filmogênica de pectina foi obtida dispersando muito lentamente a macromolécula $(4 \mathrm{~g})$ em $400 \mathrm{~mL}$ de água destilada em alta velocidade em equipamento tipo mixer Fisaton. As soluções foram aquecidas acima de $70{ }^{\circ} \mathrm{C}$ em banhomaria por $10 \mathrm{~min}$, sob agitação constante. A solução filmogênica de proteína do soro do leite foi obtida dissolvendo-se lentamente $22 \mathrm{~g}$ de proteína de soro de leite e $6,6 \mathrm{~g}$ de glicerol em $140 \mathrm{~mL}$ de água destilada. A solução foi aquecida acima de $80^{\circ} \mathrm{C}$ em banho a $90^{\circ} \mathrm{C}$ por 5 min, sob lenta agitação. Ao filme de soro de leite, foi adicionada uma macromolécula coadjuvante (gelatina) para a obtenção dos filmes, em uma proporção constante de 3 g. $100 \mathrm{~mL}^{-1}$ de solução filmogênica, mantendo-se a concentração de plastificante (glicerol). Soluções de gelatina foram preparadas separadamente, hidratando-se $6 \mathrm{~g}$ de gelatina em $60 \mathrm{~mL}$ de água destilada, seguindo-se de aquecimento em banho a $90{ }^{\circ} \mathrm{C}$ por $15 \mathrm{~min}$. As soluções formadoras de filme foram então misturadas e distribuídas em placas plexiglas de $11,8 \mathrm{~cm}$ de diâmetro com alíquotas de $20 \mathrm{~mL}$.

Após a secagem, os filmes permaneceram em dessecadores mantidos a $25^{\circ} \mathrm{C}$ e $52 \pm 2 \%$ de umidade relativa (URE), durante $48 \mathrm{~h}$ antes do início das análises, conforme Fakhouri et al. (2003) e Tanada-Palmu e Grosso (2002).

As coberturas foram aplicadas nos palitos de mandioca pela técnica de imersão por 1 min.

\subsection{Preparação do produto formatado de polpa de mandioca}

A polpa e os palitos de mandioca foram obtidos segundo as etapas desenvolvidas por Berbari (2001).

As raízes de mandioca foram submetidas às etapas de lavagem, corte e descascamento. Para a obtenção da polpa, as raízes foram cozidas em tacho com camisa de vapor por 35 min. Após a retirada dos feixes centrais, foram trituradas em equipamento tipo "cutter", por aproximadamente $40 \mathrm{~s}$. Foram acrescentados à massa de polpa de mandioca $1 \%$ de $\mathrm{NaCl}$ e $3 \%$ de óleo de milho. A massa de polpa de mandioca foi moldada em forma de palitos de $12 \mathrm{~mm}$ de diâmetro e aproximadamente $100 \mathrm{~mm}$ de comprimento em embutideira hidráulica tipo SO 30 (Rohwer, Alemanha).

\subsection{Secagem, pré-fritura, congelamento e fritura final}

A seguir, os palitos com cobertura foram submetidos à secagem em secador de bandejas sob circulação forçada de ar a $60{ }^{\circ} \mathrm{C}$ por $4 \mathrm{~h}$.

Os processos de pré-fritura e fritura final foram realizados em fritador elétrico (SIRE, São Paulo, Brasil) com capacidade de $5 \mathrm{~L}$.

Após a secagem, os palitos foram submetidos à pré-fritura em gordura vegetal hidrogenada (BUNGECukin fry) $\left(180^{\circ} \mathrm{C} / 1,5 \mathrm{~min}\right)$.

O congelamento rápido individual (IQF-Individual Quick Freezing) foi realizado em armário de congelamento a $-30{ }^{\circ} \mathrm{C}$. Os palitos pré-fritos e congelados foram então acondicionados em sacos de polietileno $(250 \mathrm{~g})$ e armazenados em congelador a $-18{ }^{\circ} \mathrm{C}$, até serem analisados posteriormente.

Após 30 dias de armazenamento congelado, as amostras foram submetidas à fritura final em gordura vegetal hidrogenada a $180{ }^{\circ} \mathrm{C}$ por $2 \mathrm{~min}$. Foram processadas porções equivalentes a $200 \mathrm{~g}$ de palitos, sendo mantida a proporção de uma parte de produto para 20 partes de gordura nas etapas de pré-fritura e fritura final. A gordura foi substituída para cada tratamento testado.

\subsection{Métodos analíticos de caracterização dos palitos de polpa de mandioca}

Após a fritura final, os palitos foram submetidos às seguintes análises de:

a) Rendimento: o rendimento do processo de fritura para cada tratamento foi calculado como a relação entre a massa frita final e a massa inicial dos palitos. Os testes foram realizados em triplicatas.

b) Transferência de gordura e umidade: os palitos de mandioca foram caracterizados quanto ao conteúdo de umidade, conforme método descrito por Horwitz (2000), e lipídeos totais (INSTITUTO ADOLFO LUTZ, 2005). Os testes foram realizados em triplicatas.

c) Cor: a cor foi determinada em colorímetro Color Eye 2020 Plus da Macbeth (Newburgh, EUA) com software COMCOR 1500Plus e janela para leitura de pequenas amostras nas condições descritas: iluminante $\mathrm{D} 65$, ângulo $10^{\circ}$, sistema de cor CIELab (parâmetros L*a*b*), calibração transmitância total. Os testes foram realizados em triplicatas.

d) Textura: a textura foi medida pela determinação da resistência ao corte em texturômetro TA-XT2 
(Stable Micro Systems, Surrey, Grã-Bretanha), operando com o software Texture Expert, modo de operação: medida da força em compressão e probe 5 bladed Kramer shear cell (HDP/KS5), velocidades de pré-teste e teste de $2 \mathrm{~mm} . \mathrm{s}^{-1}$, pós-teste de $10 \mathrm{~mm} \cdot \mathrm{s}^{-1}$ e distância de $30 \mathrm{~mm}$. Os testes foram realizados em triplicatas.

e) Propriedades sensoriais: para avaliação sensorial dos palitos de mandioca com coberturas compostas, foram realizados testes de escala estruturada verbal de nove pontos para avaliar os atributos de cor, sabor, textura da crosta e consistência interna. Foi utilizada uma equipe de 25 provadores não treinados.

\subsection{Análise estatística dos resultados}

Todos os dados foram analisados pelo método de análise de variância (ANOVA) e a comparação de médias pelo teste de Tukey, utilizando-se o software estatístico SAS (1993). As diferenças entre os tratamentos e propriedades dos filmes em um nível de $5 \%$ de probabilidade $(p \leq 0,05)$ foram consideradas significativas.

\section{Resultados e discussão}

\subsection{Caracterização da matéria-prima}

Os resultados das análises físico-químicas da raiz de mandioca in natura estão apresentados na Tabela 1. Os valores se apresentam em conformidade com os dados apresentados pela Tabela Brasileira de Composição de Alimentos-TACO (UNICAMP, 2006) de mandioca crua, exceto para o conteúdo de fibras, que se mostrou superior.

Tabela 1. Análises físico-químicas da mandioca crua.

\section{Determinações $\left(\mathbf{g} .100 \mathbf{~ g}^{-1}\right)$}

Umidade

Cinzas

Lipídios totais

Proteína $(\mathrm{N} \times 5,75)$

Fibra alimentar total

Carboidratos $^{a}$

Calorias (kcal. $\left.100 \mathrm{~g}^{-1}\right)^{\mathrm{b}}$

Acidez total (mL NaOH $1 \mathrm{~N} .100 \mathrm{~g}^{-1}$ )

Açúcares redutores

Açúcares totais

Sólidos totais

$\mathrm{pH}$

Amido

*Dados representam média de três replicatas + estimativa do desvio padrão. ${ }^{a}$ Calculado por diferença: 100 - (\%umidade + \%cinzas +

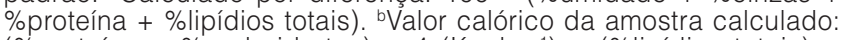
\%proteína $+\%$ carboidratos $) \times 4\left(\right.$ Kcal.g $\left.^{-1}\right)+(\%$ lipídios totais $) \times$ $9\left(\mathrm{Kcal}^{\mathrm{g}} \mathrm{g}^{-1}\right)$

\subsection{Caracterização dos filmes}

Os filmes compostos apresentaram-se visualmente homogêneos. Tanto os filmes compostos de pectina e proteína de soro de leite (PEC/SL) quanto os compostos de hidroxipropil-metil celulose e proteína de soro de leite (HP/SL) apresentaram coloração levemente amarelada a olho nu, que se tornou mais intensa quanto maior a concentração de proteína de soro de leite nas misturas. Filmes compostos de HP/SL na proporção 4:1 apresentaram pequenas bolhas na superfície, que, no entanto, não provocaram perfurações no filme. Tanto para os filmes PEC/SL quanto para os HP/SL, o aumento da concentração de proteína de soro de leite na mistura provocou um aumento na espessura dos filmes, que passou aproximadamente de 0,1 para 0,125 para filmes HP/SL. Maior aumento na espessura foi observado para filmes contendo pectina e proteína de soro de leite, em que o aumento foi de aproximadamente 100\% (Figura 1).

A solubilidade em água dos filmes diminuiu com a adição de proteína de soro de leite nas misturas (Tabela 2). Esta passou de 47,23 para $35,31 \%$ para os filmes PEC/SL e de 42,86 para $35,34 \%$ para os filmes HP/ SL. Os valores de solubilidade em água foram menores que os encontrados por Tanada-Palmu et al. (2002), em filmes compostos de celulose acetato fitalato e glúten de trigo, nos quais a solubilidade em água foi de $100 \%$. A permeabilidade ao vapor de água dos filmes foi também influenciada pela adição de proteína de soro de leite às misturas. Para os filmes PEC/SL, com a adição de proteína de soro de leite, houve um aumento no valor da permeabilidade; isso pode ter ocorrido pelo aumento da espessura provocado pelo aumento da concentração de SL na mistura. Para os filmes compostos de HP/ SL (Tabela 2), houve uma redução significativa nesse atributo. Como discutido anteriormente, os filmes compostos HP/SL na concentração 4:1 apresentaram uma grande quantidade de bolhas na superfície, o que pode ter influenciado no valor de permeabilidade ao vapor de água desses filmes, uma vez que estas bolhas facilitam a difusão da umidade pela superfície do filme, diminuindo assim sua propriedade de barreira

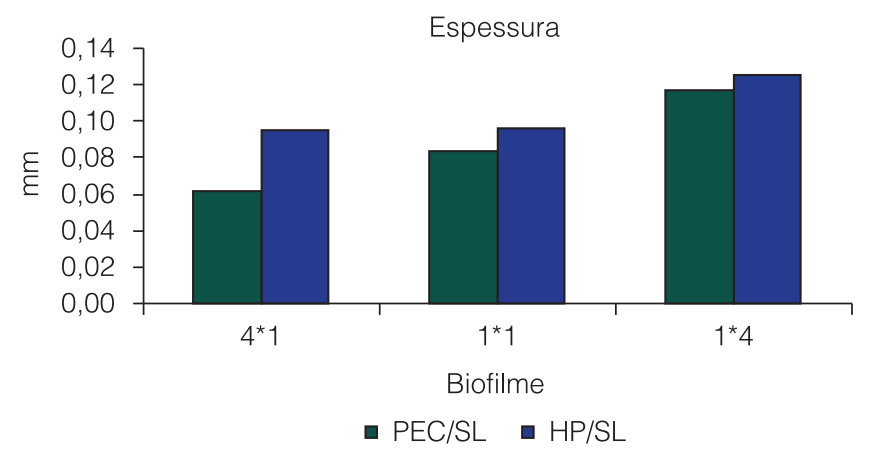

Figura 1. Espessura dos filmes compostos. 
Utilização de coberturas comestíveis para redução de absorção de gordura em produtos estruturados pré-fritos congelados de mandioca

BERBARI, S. A. G. et al.

Tabela 2. Permeabilidade ao vapor de água e solubilidade em água dos filmes compostos

\begin{tabular}{|c|c|c|c|}
\hline Filmes & Proporção & $\begin{array}{l}\text { Permeabilidade ao vapor de } \\
\text { água }\left(\mathrm{gmm} \cdot \mathrm{m}^{-2} \mathrm{dkPa}\right)^{\star \star}\end{array}$ & Solubilidade em água $(\%)^{\star *}$ \\
\hline \multirow[t]{3}{*}{ PEC/SL } & $4: 1$ & $6,19 \pm 0,49 c$ & $47,23 \pm 3,41^{a}$ \\
\hline & $1: 1$ & $9,86 \pm 1,24^{b}$ & $35,43 \pm 0,17^{b}$ \\
\hline & $1: 4$ & $9,16 \pm 1,59^{b}$ & $35,31 \pm 1,04^{b}$ \\
\hline \multirow[t]{3}{*}{ HP/SL } & $4: 1$ & $17,23 \pm 0,41^{a}$ & $42,86 \pm 0.79^{a}$ \\
\hline & $1: 1$ & $12,32 \pm 0,24^{b}$ & $36,93 \pm 0,57^{b}$ \\
\hline & $1: 4$ & $5,59 \pm 0,65^{c}$ & $35,34 \pm 1,00^{b}$ \\
\hline
\end{tabular}

$\mathrm{HP}=$ hidroxipropil-metil celulose; $\mathrm{PEC}=$ pectina; $\mathrm{SL}=$ proteína de soro de leite. ${ }^{*}$ Média e desvio padrão de triplicatas. ${ }^{\mathrm{a}-\mathrm{c} M e ́ d i a s}$ com letras iguais não diferem no nível de $p \leq 0,05$.

ao vapor de água. Essas bolhas se originaram durante a elaboração da solução filmogênica de HP, pois esta solução foi obtida por meio de alta agitação. Menores valores de PVA foram observados para filmes PEC/SL na proporção 4:1 (6,19 gmm. $\left.\mathrm{m}^{-2} \mathrm{dkPa}\right)$ e, para filmes HP/ SL na proporção 1:4 (5,59 gmm. $\left.\mathrm{m}^{-2} \mathrm{dkPa}\right)$, esses valores foram maiores que os encontrados por Briston (1988) e Smith (1986) em filmes de polietileno de alta densidade, nos quais o valor de PVA foi de $0,02 \mathrm{gmm} \cdot \mathrm{m}^{-2} \mathrm{dkPa}$.

Filmes elaborados com pectina e proteína de soro de leite (PEC/SL) apresentaram maiores valores de resistência à tração que os elaborados com hidroxipropilmetil celulose e proteína de soro de leite (HP/SL) nas proporções 4:1 e 1:1 (Figura 2). Enquanto filmes PEC/ SL (4:1) apresentaram valores de resistência à tração de 14,8 MPa, filmes HP/SL na mesma proporção (4:1) apresentaram valores de resistência à tração de 4,83 MPa; na proporção 1:1, essa diferença foi menos acentuada, e, na proporção 1:4, esses valores foram semelhantes (5,55 e 5,83 MPa para filmes PEC/SL e HP/ $\mathrm{SL}$, respectivamente). Os valores encontrados foram menores que os encontrados para polietileno de alta densidade, no qual a resistência à tração varia de 17,3 a 34,6 MPa (BRISTON, 1988; SMITH, 1986). Ao contrário da resistência à tração, a elongação dos filmes compostos PEC/SL aumentou quando a proporção de proteína de soro de leite foi maior na mistura, sendo que a elongação dos filmes passou de 3,77 para 9,38\%. A adição de proteína de soro de leite, no entanto, provocou uma diminuição na elongação dos filmes HP/SL, que passou de 16,82\% na proporção 4:1 para 4,62\% na proporção 1:4.

A adição de proteína de soro de leite nos filmes provocou - tanto para os filmes PEC/SL quanto para os filmes HP/SL (Figura 3) - diminuição da opacidade. Em geral, todos os filmes apresentaram um alto valor de opacidade, sendo que a maior variação de opacidade foi observada para filmes compostos HP/SL, nos quais a opacidade passou de 91 para $82 \%$, enquanto nos filmes PEC/SL, a opacidade passou de 87 para $80 \%$.

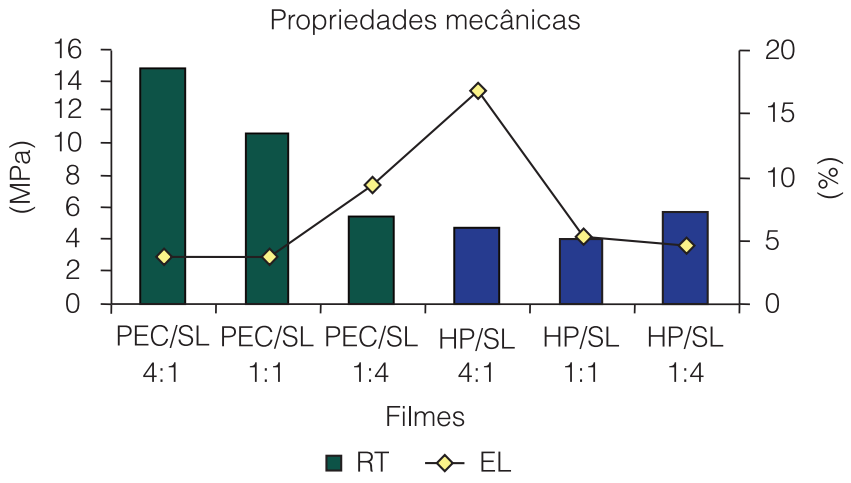

Figura 2. Propriedades mecânicas dos filmes: resistência à tração (RT) e elongação (EL).

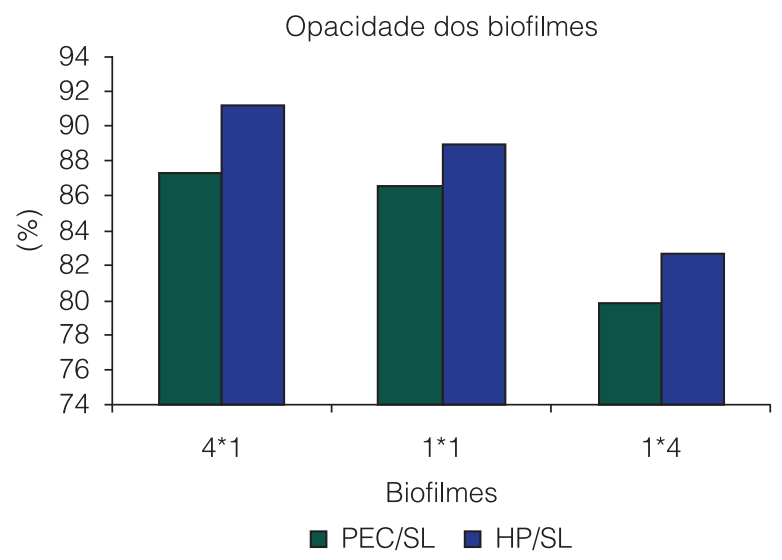

Figura 3. Opacidade dos filmes.

\subsection{Efeito da aplicação de coberturas compostas comestíveis no produto formatado de polpa de mandioca pré-frito e congelado}

\subsubsection{Transferência de gordura e umidade}

Os resultados dos teores de umidade e lipídios dos palitos de mandioca com coberturas compostas são apresentados na Tabela 3. 
Utilização de coberturas comestíveis para redução de absorção de gordura em produtos estruturados pré-fritos congelados de mandioca

BERBARI, S. A. G. et al.

De forma geral, todas as coberturas compostas avaliadas demonstraram eficiência quanto à redução da absorção de gordura quando comparadas à amostra controle. O melhor resultado quanto à eficiência na diminuição de gordura foi obtido pela cobertura HP/SL 1:4 (hidroxipropil-metil celulose e proteína de soro de leite).

Pode-se verificar na Tabela 4 que, quando comparada ao controle, a amostra HP/SL 1:4 apresentou uma percentagem de redução de 32,3\%, assim como a menor redução do teor de umidade nas etapas de pré-fritura e fritura final. Um menor teor de absorção de gordura em conjunto com baixa redução de umidade são fatores que agem positivamente sobre a qualidade dos produtos fritos.

\subsubsection{Análises físicas - avaliação objetiva de textura e cor}

A Tabela 5 apresenta os resultados da avaliação objetiva de textura - teste de resistência ao corte dos palitos de mandioca com coberturas compostas, após 3 min de fritura final. A amostra Controle apresentou a menor resistência ao corte e diferiu significativamente das amostras com coberturas compostas. Estes resultados demonstram que a aplicação de coberturas alterou a textura da crosta dos palitos de mandioca, tornando-os mais resistentes ao corte. A amostra HP/SL 1:4 diferiu significativamente $(p<0,05 \%)$ da amostra PEC/SL 4:1 quanto à resistência ao corte. As amostras PEC/SL 1:1 e 1:4, e HP/SL 1:1, 4:1 e 1:4 apresentaram resultados intermediários, não diferindo significativamente das amostras HP/SL 1:4 e PEC/SL 4:1.

A Tabela 6 apresenta os resultados da avaliação objetiva de cor dos palitos de mandioca cobertos com coberturas compostas, após fritura final. No que diz respeito à cor, não houve diferença significativa $(p<0,05)$ entre as amostras quanto á luminosidade $\left(L^{*}\right)$. O Controle apresentou tom vermelho $\left(+\mathrm{a}^{*}\right)$ significativamente menos intenso do que as amostras PEC/SL 1:1, PEC/SL 1:4 e HP/ SL 1:1, 1:4 e 4:1, mas não diferiu da PEC/SL 4:1. Quanto à tonalidade amarela $\left(+b^{*}\right)$, a amostra Controle apresentou tom significativamente menos intenso do que PEC/SL 1:1 e 1:4, e HP/SL 1:1 e 1:4, mas não diferiu de PEC/SL 4:1 e HP/SL 4:1. De maneira geral, a adição de proteína de soro de leite provocou alterações de cor nos palitos de mandioca. As amostras com maiores teores de proteína de soro de leite PEC/SL e HP/SL nas proporções 1:1 (50\%) e $1: 4(80 \%)$ apresentaram maiores valores para os parâmetros $+a \mathrm{e}+\mathrm{b}$, indicando maior intensidade de cor dourada, por causa da reação de Maillard, que foi mais intensa nestes casos, pela presença de açúcares redutores e aminoácidos presentes no soro de leite. A

Tabela 3. Conteúdo de umidade e lipídios totais de palitos formatados de polpa de mandioca pré-fritos e após fritura final.

\begin{tabular}{|c|c|c|c|c|}
\hline \multirow[t]{2}{*}{ Filmes } & \multicolumn{2}{|c|}{ Pré-fritos } & \multicolumn{2}{|c|}{ Após fritura final } \\
\hline & Umidade $\left(\mathrm{g} .100 \mathrm{~g}^{-1}\right)$ & Lipídios $\left(\mathrm{g} .100 \mathrm{~g}^{-1}\right)$ & Umidade $\left(g .100 \mathrm{~g}^{-1}\right)$ & Lipídios $\left(\mathrm{g} .100 \mathrm{~g}^{-1}\right)$ \\
\hline Controle & $50,29^{a, A}$ & $8,17^{b, A}$ & $46,48^{b, A}$ & $10,37^{\mathrm{a}, \mathrm{A}}$ \\
\hline PEC/SL 1:1 & $44,43^{a, D E}$ & $6,68^{\mathrm{b}, \mathrm{CD}}$ & $41,89^{b, c}$ & $8,36^{\mathrm{a}, \mathrm{c}}$ \\
\hline PEC/SL 4:1 & $43,95^{a, E}$ & $7,18^{b, B}$ & $38,67^{b, E}$ & $9,10^{\mathrm{a}, \mathrm{B}}$ \\
\hline PEC/SL 1:4 & $44,65^{\mathrm{a}, \mathrm{DE}}$ & $6,86^{b, c}$ & $41,10^{b, D}$ & $9,02^{a, B}$ \\
\hline HP/SL 1:1 & $45,48^{a, c}$ & $6,62^{\mathrm{b}, \mathrm{CD}}$ & $42,16^{\mathrm{b}, \mathrm{B}, \mathrm{c}}$ & $7,93^{\mathrm{a}, \mathrm{D}}$ \\
\hline HP/SL 4:1 & $46,39^{a, B}$ & $5,57^{\mathrm{b}, \mathrm{E}}$ & $41,22^{b, D}$ & $8,20^{\mathrm{a}, \mathrm{CD}}$ \\
\hline HP/SL 1:4 & $45,02^{a, C D}$ & $6,57^{b, D}$ & $42,47^{b, B}$ & $7,02^{\mathrm{a}, \mathrm{E}}$ \\
\hline
\end{tabular}

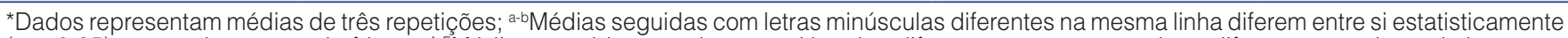
$(\mathrm{p} \leq 0,05)$ quanto às etapas de fritura; A-EMédias seguidas com letras maiúsculas diferentes na mesma coluna diferem entre si estatisticamente $(\mathrm{p} \leq 0,05)$ quanto ao tratamento (tipo de cobertura); PEC/SL: pectina e proteína de soro de leite; HP/SL: hidroxipropil metil celulose e proteína de soro de leite.

Tabela 4. Transferência de lipídios e umidade através das coberturas compostas.

\begin{tabular}{cccccc} 
Filmes & \multicolumn{2}{c}{ Lipídios } & & \multicolumn{2}{c}{ Umidade } \\
\cline { 2 - 3 } \cline { 5 - 6 } & \% Redução & $\begin{array}{c}\text { \% Absorção } \\
\text { (entre amostras) }\end{array}$ & & $\begin{array}{c}\text { \% Redução } \\
\text { (em relação ao controle) }\end{array}$ & \% Redução \\
Controle & - & 26,92 & - & 7,80 \\
PEC/SL 1:1 & 19,38 & 21,15 & 9,61 & 5,60 \\
PEC/SL 4:1 & 12,24 & 26,74 & 16,37 & 11,70 \\
PEC/SL 1:4 & 12,92 & 35,56 & 11,67 & 8,20 \\
HP/SL 1:1 & 23,52 & 19,80 & 8,92 & 7,14 \\
HP/SL 4:1 & 20,92 & 47,21 & 11,06 & 10,92 \\
HP/SL 1:4 & 32,30 & 6,87 & 9,01 & 6,28 \\
\hline
\end{tabular}

*Dados representam médias de três repetições; PEC/SL: pectina e proteína de soro de leite; HP/SL: hidroxipropil-metil celulose e proteína de soro de leite. 
Utilização de coberturas comestíveis para redução de absorção de gordura em produtos estruturados pré-fritos congelados de mandioca

BERBARI, S. A. G. et al.

partir destes resultados optou-se pela diminuição do tempo de fritura final dos palitos para 2 min.

\subsubsection{Avaliação sensorial}

A Tabela 7 apresenta os resultados da avaliação sensorial dos palitos de mandioca cobertos com coberturas compostas após fritura final. Foram avaliados os atributos de cor, sabor, textura e consistência interna. Do ponto de vista sensorial, as amostras com coberturas compostas quando comparadas com a amostra controle apresentaram diferença significativa quanto à cor para a amostra PEC/SL 1:4, que obteve nota média de 5,06, correspondente ao intervalo entre os termos "6" - ligeira

Tabela 5. Resistência ao corte dos palitos de polpa de mandioca após fritura final.

\begin{tabular}{cc}
\hline Filmes & Resistência ao corte (N)* \\
\hline Controle & $105,4 \pm 7,3^{\mathrm{c}}$ \\
PEC/SL 1:1 & $157,4 \pm 8,2^{\mathrm{ab}}$ \\
PEC/SL 4:1 & $153,9 \pm 12,4^{\mathrm{b}}$ \\
PEC/SL 1:4 & $155,2 \pm 9,5^{\mathrm{ab}}$ \\
HP/SL 1:1 & $156,5 \pm 8,5^{\mathrm{ab}}$ \\
HPSL 4:1 & $163,0 \pm 11,8^{\mathrm{ab}}$ \\
HP/SL 1:4 & $168,0 \pm 7,9^{\mathrm{a}}$ \\
\hline
\end{tabular}

*Dados representam médias de dez determinações analíticas \pm estimativa de desvio padrão; Médias seguidas com letras iguais na mesma coluna não diferem entre si estatisticamente $(p \leq 0,05)$ quanto ao tratamento (tipo de cobertura): PEC/SL: pectina e proteína de soro de leite; HP/SL: hidroxipropil metil celulose e proteína de soro de leite. uniformidade - e "5" - muito clara ou muito escura - da escala utilizada. Estes resultados coincidem com a avaliação de cor objetiva, que também indicaram que esta amostra apresentava coloração mais escura dentre as amostras PEC/SL. O uso das coberturas compostas não afetou o sabor das amostras, que não diferiram significativamente da amostra controle e obtiveram notas médias correspondentes aos termos "8" - Típico de mandioca frita agradável - e "7" - Típico, sem sabor estranho. Quanto à textura, a amostra HP/SL 4:1 diferiu significativamente da amostra controle e foi considerada pela equipe de provadores como "ligeiramente dura, mais ainda agradável". Estes resultados coincidem com os resultados da avaliação objetiva da textura. Para o atributo "consistência interna", esta amostra também diferiu significativamente da amostra controle e obteve média de 6,25, que corresponde ao termo "ligeiramente consistente e menos uniforme, mas ainda agradável" da escala utilizada.

\section{Conclusões}

As características de permeabilidade ao vapor de água, solubilidade em água e espessura das coberturas influenciaram a capacidade de retenção de umidade do produto durante o processo de fritura. Foi observada maior redução de umidade proporcional ao aumento da concentração filmogênica de PEC e HP nas misturas, indicando que uma maior retenção de umidade foi

Tabela 6. Parâmetros de cor $\left(L^{*}, a^{*} e b^{*}\right)$ de palitos de polpa de mandioca após fritura final.

\begin{tabular}{cccc} 
Filmes & $\mathbf{L}^{*}$ & $\mathbf{a}^{*}$ & $\mathbf{b}^{*}$ \\
Controle & $48,25 \pm 3,35^{\mathrm{a}}$ & $2,40 \pm 0,66^{\mathrm{b}}$ & $19,56 \pm 0,69^{\mathrm{b}}$ \\
PEC/SL 1:1 & $50,38 \pm 1,42^{\mathrm{a}}$ & $4,33 \pm 1,56^{\mathrm{a}}$ & $24,58 \pm 2,51^{\mathrm{a}}$ \\
PEC/SL 4:1 & $49,47 \pm 1,66^{\mathrm{a}}$ & $2,82 \pm 0,67^{\mathrm{ab}}$ & $21,93 \pm 1,49^{\mathrm{ab}}$ \\
PEC/SL 1:4 & $47,68 \pm 1,54^{\mathrm{a}}$ & $5,09 \pm 1,22^{\mathrm{a}}$ & $25,43 \pm 1,88^{\mathrm{a}}$ \\
HP/SL 1:1 & $47,32 \pm 2,59^{\mathrm{a}}$ & $4,73 \pm 1,51^{\mathrm{a}}$ & $25,17 \pm 1,80^{\mathrm{a}}$ \\
HP/SL 4:1 & $48,99 \pm 3,97^{\mathrm{a}}$ & $4,74 \pm 1,87^{\mathrm{a}}$ & $23,61 \pm 3,36^{\mathrm{ab}}$ \\
HP/SL 1:4 & $45,89 \pm 2,16^{\mathrm{a}}$ & $4,47 \pm 0,91^{\mathrm{a}}$ & $24,04 \pm 1,57^{\mathrm{a}}$ \\
\hline
\end{tabular}

*Dados representam médias de cinco determinações analíticas \pm estimativa de desvio padrão; Médias seguidas com letras iguais na mesma coluna não diferem entre si estatisticamente $(p \leq 0,05)$ quanto ao tratamento (tipo de cobertura); PEC/SL: pectina e proteína de soro de leite; HP/ SL: hidroxipropil metil celulose e proteína de soro de leite.

Tabela 7. Resultados da avaliação sensorial dos palitos de mandioca cobertos com coberturas compostas após fritura final.

\begin{tabular}{|c|c|c|c|c|}
\hline Filmes & Cor & Sabor & Textura & Consistência interna \\
\hline Controle & $8,25^{a}$ & $7,94^{\mathrm{a}}$ & $8,22^{a}$ & $8,00^{a}$ \\
\hline PEC/SL 1:1 & $7,62^{\mathrm{a}}$ & $7,31^{\mathrm{a}}$ & $7,08^{a b}$ & $7,62^{a b}$ \\
\hline PEC/SL 1:4 & $5,06^{b}$ & $7,50^{\mathrm{a}}$ & $7,81^{a}$ & $7,31^{a b}$ \\
\hline HP/SL 1:1 & $7,50^{a}$ & $7,44^{\mathrm{a}}$ & $7,50^{a b}$ & $7,00^{a b}$ \\
\hline HP/SL 4:1 & $7,31^{a}$ & $7,31^{a}$ & $6,31^{b}$ & $6,25^{b}$ \\
\hline HP/SL 1:4 & $7,12^{\mathrm{a}}$ & $7,56^{\mathrm{a}}$ & $7,75^{\mathrm{a}}$ & $7,12^{\mathrm{ab}}$ \\
\hline
\end{tabular}

Médias seguidas com letras iguais na mesma coluna não diferem entre si estatisticamente ( $p \leq 0,05)$ quanto ao tratamento (tipo de cobertura); PEC/SL: pectina e proteína de soro de leite; HP/SL: hidroxipropil metil celulose e proteína de soro de leite. 
Utilização de coberturas comestíveis para redução de absorção de gordura em produtos estruturados pré-fritos congelados de mandioca

BERBARI, S. A. G. et al.

obtida pelas coberturas de menor concentração destas macromoléculas (1:1) e de menor permeabilidade ao vapor de água. A adição de proteína de soro de leite nos filmes provocou diminuição da opacidade tanto para os filmes compostos de pectina e proteína de soro de leite (PEC/SL) quanto para os filmes compostos por hidroxipropil-metil celulose e proteína de soro de leite $(\mathrm{HP} / \mathrm{SL})$.

A aplicação das coberturas compostas alterou a textura e a cor dos palitos de mandioca (analisadas de forma objetiva), tornando-os mais rígidos e com coloração mais intensa. Do ponto de vista sensorial, o sabor dos palitos de mandioca não foi afetado pela aplicação de coberturas compostas.

Quanto à redução da absorção de gordura, a cobertura mais eficiente foi aquela elaborada com hidroxipropil-metil celulose e soro de leite (HP/SL) na proporção 1:4, promovendo uma redução de $32,3 \%$ do teor de gordura, quando comparada com o produto sem cobertura.

\section{Agradecimentos}

À FAPESP, pelo apoio financeiro.

\section{Referências}

AMERICAN SOCIETY FOR TESTING AND MATERIAL - ASTM. Standard test methods for water vapor transmission of materials. West Conshohocken: ASTM, 1995. 42p. (ASTM E 96).

BERBARI, S.A.C. Desenvolvimento de Tecnologia para Obtenção de Produto Formatado e Congelado de Mandioca (Manihot Esculenta Crantz). 2001. 119 f. Tese (Doutorado em Tecnologia de Alimentos)-Faculdade de Engenharia de Alimentos, Universidade Estadual de Campinas, Campinas.

BERTAN, L. C. Desenvolvimento e Caracterização de Filmes Simples e Compostos a Base de Gelatina, Ácidos Graxos e Breu Branco. 2003. 157 f. Dissertação (Mestrado em Alimentos e Nutrição)-Faculdade de Engenharia de Alimentos, Universidade Estadual de Campinas, Campinas.

BRISTON, J. H. Plastic Films. 3.ed. New York: John Wiley, Inc., 1988. 434p.

DIEMAIR, W. Laboratoriumsbuch fur Lebensmittel-Chemiker. 8. aufl. Drisden: Verlag von Theodor Steinkopff, 1963. 804p.

FAKHOURI, F. M.; BATISTA, J. A.; GROSSO, C. R. F. Desenvolvimento e caracterização de filmes comestíveis de gelatina, triacetina e ácidos graxos. Brazilian Journal of Food Technology, Campinas, v. 6, n. 2, p. 301-308, 2003.

GONTARD, N.; DUCHEZ, C.; CUQ, J. L.; GUILBERT, S. Edible composite films of wheat gluten and lipids: water vapor permeability and other physical properties. International Journal of Food Science and Technology, Malden, v. 29, n. 1, p. 39-50, 1994. http://dx.doi.org/10.1111/j.1365-2621.1994. tb02045.x

HORWITZ, W. Official Methods of Analysis of Association of Analytical Chemists. 17. ed. Gaithersburg, Maryland: AOAC, 2000. $1018 \mathrm{p}$.

HUNTERLAB. The Color Management Company, Universal softwar. Version 3.2. Reston, 1997.

INSTITUTO ADOLFO LUTZ. Normas Analíticas do Instituto Adolfo Lutz: métodos químicos e físicos para análise de alimentos. 3. ed. São Paulo: Editora do Instituto Adolfo Lutz, 1985. $533 \mathrm{p}$.

INSTITUTO ADOLFO LUTZ. Normas Analíticas do Instituto Adolfo Lutz: métodos químicos e físicos para análise de alimentos. 4. ed. Brasília: Editora do Instituto Adolfo Lutz, 2005. $1018 \mathrm{p}$.

KROCHTA, J. M.; BALDWIN, E. A.; NISPEROS-CARRIERO, M. O. Edible Coatings and Films to Improve Food Quality. Lancaster: Technomic Publishing Co., 1994. 379 p.

KROCHTA, J. M.; MULDER-JOHNSON, C. M. Edible and biodegradable polymer films: Challenges and opportunities. Food Technology, Chicago, v. 51, n. 2, p. 61-74, 1997.

MALLIKARJUNAN, P.; CHINNAN, M. S.; BALASUBRAMANIAM, V. M.; PHILLIPS, R. D. Edible coatings for deep-fat frying of starchy products. Lebensmittel-Wissenschaft\&Technologie, Oxford, v. 30, n. 7, p. 709-714, 1997.

MELLEMA, M. Mechanism and reduction of fat uptake in deep-fat fried foods.Trends in Food Science \& Technology, Oxford, v. 14, n. 9, p. 364-373, 2003.

STATISTICAL ANALISYS SYSTEM INSTITUTE-SAS. SAS User's Guide: statistics. Cary: SAS Institute, 1993.

SMITH, O. B. Why Extrusion cooking? Cereal Foods World, St. Paul, v. 21, n. 1, p. 4-7, 1986.

TANADA-PALMU, P. S.; GROSSO, C. R. F. Wheat gluten composite and bilayer edible films: effect of lipid addition. In: Research Advances in Agricultural \& Food Chemistry, Ed. Global Research Network, p. 19-26, 2002.

TANADA-PALMU, P. S.; FAKHOURI, F. M.; GROSSO, C. R. F. Filmes biodegradáveis: extensão da vida útil de frutas tropicais. Biotecnologia: Ciência \& Desenvolvimento, Brasilia, v. 5, n. 26, p. 12-17, 2002.

UNIVERSIDADE DE CAMPINAS-UNICAMP. Tabela Brasileira de Composição de Alimentos-TACO. Versão 2. 2. ed. Campinas: UNICAMP/NEPA, 2006. 